\section{Risk of measles \\ transmission on \\ aeroplanes: Australian experience 2007-2011}

To THE EDITOR: We thank Hoad and colleagues for presenting data from Australian states and territories regarding in-flight exposure to measles. ${ }^{1}$

The current cases in Queensland, Victoria and New South Wales, which have included domestic air travel, ${ }^{2}$ highlight the challenges measles still holds for Australia. Hoad et al's report outlines the substantial public health response that such air travel events generate, despite the low likelihood of being able to use postexposure prophylaxis (PEP), measles-mumpsrubella vaccine or immunoglobulin in exposed contacts. They suggest that direct email or text messaging of passengers should be considered as an alternative to routine contact tracing, but identify that contact information is not always available to health departments.

Given this, we recommend that airlines be made responsible for alerting passengers in the event of an urgent public health concern, such as potential exposure to measles.

This would require airlines to keep travel manifests for at least 14 days after a flight. Potentially exposed passengers could be directed to a health department website providing information about PEP options, use and access - for example, through their general practitioner - as well as self-monitoring for measles symptoms, and, should symptoms occur, social distancing measures.

Airlines already use social media and email to communicate with customers, and, we believe, have a duty of care to passengers that extends beyond safe arrival at their travel destination. Measles is a serious illness that leads to hospitalisation of around one-third of affected young adults in Australian outbreaks. ${ }^{3-6}$ Making airlines, as the primary holders of travellers' details, responsible for initial contact would minimise delays and communication errors and maximise the likelihood of preventing further generations of infection in the wider community.

Stephen B Lambert Medical Epidemiologist ${ }^{1}$ Frank H Beard Public Health Physician² 1 Queensland Children's Medical Research Institute, Brisbane, QLD.

2 Communicable Diseases Unit, Queensland Health, Brisbane, QLD.

sblambert@uq.edu.au

Competing interests: No relevant disclosures. Online first 04/09/13

doi: 10.5694/mjal3.10434

1 Hoad VC, O'Connor BA, Langley AJ, Dowse GK. Risk of measles transmission on aeroplanes: Australian experience 2007-2011. Med J Aust 2013; 198: 320-323.

2 Australian Associated Press. Tourist sparks east coast measles warning. 2013; 28 Aug. http:// www.news.com.au/breaking-news/national/ measles-warning-for-qantas-passengers/storye6frfku9-1226705699100 (accessed Sep 2013).

3 Lambert SB, Kelly HA, Andrews RM, et al. Enhanced measles surveillance during an interepidemic period in Victoria. Med J Aust 2000; 172: 114-118.

4 Lambert SB, Morgan ML, Riddell MA, et al. Measles outbreak in young adults in Victoria, 1999. Med J Aust 2000; 173: 467-471.

5 Davidson N, Andrews R, Riddell M, et al. A measles outbreak among young adults in Victoria, February 2001. Commun Dis Intell 2002; 26: 273-278.

6 Jayamaha J, Binns PL, Fennell M, et al. Laboratory diagnosis, molecular characteristics, epidemiological and clinical features of an outbreak of measles in a low incidence population in Australia. J Clin Virol 2012; 54: 168-173. 